\title{
Escala de Práticas Pedagógicas para a Criatividade no Ensino Fundamental: Estudo Preliminar de Validação ${ }^{1}$
}

\author{
Eunice Maria Lima Soriano de Alencar \\ Denise Souza Fleith \\ Universidade de Brasília
}

\begin{abstract}
RESUMO
Este estudo teve como objetivo construir e validar uma escala de práticas pedagógicas para a criatividade no ensino fundamental. A escala, com 36 itens, foi aplicada em 398 professores, das quatro primeiras séries de escolas públicas e particulares. Foi efetuada análise fatorial, que gerou os seguintes fatores: Estímulo à Produção de Novas Idéias, Interesse pela Aprendizagem do Aluno, Participação do Aluno em Sala de Aula, Incentivo à Autoconfiança do Aluno, Procedimentos Tradicionais de Ensino, Valorização das Idéias Discentes e Promoção da Auto-Avaliação Discente. Os coeficientes de fidedignidade variaram de 0,51 a 0,69 , o que indica a necessidade de revisão da escala, com inclusão de novos itens e investigações com amostras distintas. Este instrumento pode vir a contribuir para a identificação de crenças e idéias errôneas de professores sobre procedimentos úteis para o desenvolvimento da criatividade em sala de aula.
\end{abstract}

Palavras-chave: professor, escola, avaliação de práticas pedagógicas.

\begin{abstract}
Scale of Pedagogical Practices for Creativity in Elementary School: Preliminary Study of Validity

The purpose of this study was to design and validate a scale of pedagogical practices for creativity in elementary school. The 36 item scale, was administered to $3981^{\text {st }}$ to $4^{\text {th }}$ grade public and private elementary school teachers. An exploratory factor analysis was carried out, identifying seven factors: Incentive to the Production of New Ideas, Interest for the Student's Learning, Student's Participation in the Classroom, Incentive to the Student's Self-Confidence, Traditional Teaching Practices, Valuation of Student's Ideas and Promotion of Student's Self-Evaluation. The reliability coefficients varied from .51 to .69 , which indicates the need for scale reformulation, with the inclusion of new items and further studies. This instrument may help in the identification of teachers' beliefs and misconceptions about useful procedures for the development of creativity in the classroom.
\end{abstract}

Keywords: teacher, school, evaluation of educational practices.

Na área de pesquisa em criatividade, a importância e necessidade de instrumentos de medida têm sido documentadas desde o artigo clássico de Guilford (1950) sobre criatividade, considerado como ponto de partida para um maior interesse na investigação deste fenômeno complexo e multifacetado (Isaksen, 1987; Urban, 1990). Nesse artigo, que foi lido por Guilford quando assumiu a presidência da Associação Americana de Psicologia, é destacado o papel crítico da criatividade para a realização do potencial humano, paralelamente ao descaso por parte dos psicólogos norteamericanos pelo estudo deste fenômeno fascinante.

Nestas últimas décadas, um volume substancial de pesquisas foi realizado, focalizando tanto atributos pessoais que se associam à criatividade, como distintos aspectos do processo e do produto criativos, recebendo maior atenção, em anos recentes, elementos do ambiente sócio-histórico cultural que têm influência na expressão, desenvolvimento e reconhecimento da criatividade (Alencar \& Fleith, 2003; Amabile, 1996; Craft, 2005; Cropley, 2004; Csikszentmihalyi, 1999; Runco, 2004).

A complexa rede de interações entre elementos do indivíduo e variáveis sociais, culturais e históricas, do ambiente onde o mesmo se encontra inserido, passou também a ser ressaltada em distintas abordagens, como nas contribuições teóricas de Sternberg (1988, 1991; Sternberg \& Lubart, 1991, 1993, 1995, 1996), 
Amabile (1983, 1990, 2001; Hill \& Amabile, 1993) e Csikszentmihalyi (1988, 1994, 1995, 1999). Sternberg, por exemplo, considera que um modelo completo deste fenômeno deve incluir tanto fatores do ambiente como variáveis pessoais que facilitam ou impedem a manifestação da criatividade, concebendo o comportamento criativo como resultado da convergência de seis fatores distintos e inter-relacionados, apontados como recursos necessários para a expressão criativa. Estes seriam: (a) inteligência, (b) estilos intelectuais, (c) conhecimento, (d) personalidade, (e) motivação e (f) contexto ambiental.

Ao descrever estes distintos fatores, Sternberg e Lubart (1991) salientam que nem todos os elementos de cada um desses recursos são igualmente relevantes para a criatividade, devendo ainda cada um deles ser visto de forma interativa com os demais e jamais de forma isolada. Com relação ao contexto ambiental, lembram Sternberg e Lubart que a criatividade não ocorre no vácuo, especialmente porque tanto a pessoa como o produto são julgados e avaliados como criativos ou não por pessoas do seu meio social. Entretanto, o tipo de ambiente que facilita o desenvolvimento e realização do potencial criativo depende também de outros fatores, como, por exemplo, do nível do potencial criativo da pessoa e da área em que a pessoa criativa se expressa. Desta forma, o ambiente que facilita a expressão criativa interage com variáveis pessoais e situacionais de uma forma complexa.

Também Amabile (1983, 1990, 2001) aponta o papel crucial de fatores sociais e ambientais para a performance criativa. Em seu Modelo Componencial da Criatividade, propõe três distintos componentes considerados necessários para o trabalho criativo em qualquer domínio: habilidades de domínio (relacionados à expertise em um domínio), processos criativos relevantes (estratégias e estilos que favorecem a produção de novas idéias, além de traços de personalidade) e motivação intrínseca, considerando que todos estes componentes sofrem uma influência social marcante. Esta autora examinou autobiografias, cartas e registros de cientistas, artistas, escritores e outros profissionais reconhecidos pelas suas contribuições criativas. Por meio desta análise, constatou o impacto de variáveis situacionais e do contexto sócio-histórico, tendo ainda identificado casos de indivíduos com alta competência, conhecimento e habilidades cognitivas, cuja produção criativa foi reduzida e prejudicada por condições sociais e ambientais adversas.
De forma similar, Csikszentmihalyi (1988, 1999), em sua teoria sistêmica da criatividade, inclui forças sociais, culturais e pessoais para explicar o fenômeno da criatividade, ressaltando que o impacto destas forças na criatividade tem sido geralmente subestimado. Este autor propôs uma mudança de foco no estudo da criatividade, sinalizando a necessidade de se abandonar a visão da criatividade que tem a pessoa como centro para um modelo, no qual a pessoa é parte de um sistema de influências.

Paralelamente ao reconhecimento crescente da criatividade como um fenômeno tanto social como individual, tem sido ressaltada a necessidade de se propiciar condições favoráveis ao desenvolvimento da capacidade de criar, de tornar a educação mais criativa, oferecendo-se práticas efetivas que levem a um desenvolvimento mais pleno do potencial criador. Isto se justifica em função de um mundo em rápidas mudanças, marcado pela instabilidade e incerteza, que requer habilidades, atitudes e valores para lidar criativamente com novos problemas (Torrance, 1993).

Há uma vasta literatura sobre características do professor facilitador da criatividade e a respeito do que o docente deve fazer para promover o desenvolvimento do potencial criador de seus alunos (Alencar \& Fleith, 2003; Amabile, 1989; Starko, 1995). Entretanto, muito pouco se pesquisou sobre o que o professor de fato considera como relevante de ser implementado em sala de aula para favorecer o desenvolvimento da capacidade de criar de seus alunos, observando-se um número muito limitado de estudos a respeito da percepção docente sobre práticas pedagógicas que efetivamente promovem a criatividade.

Ademais, tais estudos, com exceção do desenvolvido por Tan (2001) em Singapura, foram realizados com um número muito reduzido de professores. Fleith (2000), por exemplo, que investigou a percepção de professores e alunos norte-americanos sobre criatividade em sala de aula, teve como participantes do seu estudo sete professores, os quais foram entrevistados a respeito do ambiente em sala de aula que promove ou inibe a criatividade e estratégias e atividades utilizadas em classe para fortalecer a criatividade do aluno, entre outros aspectos. Fleith constatou que os professores, ao descrever um ambiente que fortalece a criatividade, apontaram tanto atitudes do professor, como estratégias e atividades diversas a serem implementadas em sala de aula. Morgan e Foster (1999) identificaram, junto a 20 professores australianos, as estraté- 
gias para promover a criatividade em sala de aula. Estes pesquisadores observaram que os professores se referiram especialmente à técnica de tempestade de idéias e ao uso de questões abertas para desenvolver o pensamento criativo de seus alunos. Morgan e Foster identificaram também vários obstáculos que, segundo os professores, os impedem de promover a criatividade em sala de aula, como falta de tempo, problemas comportamentais e ausência de referências sobre criatividade.

Melo (2001) entrevistou 12 professores de Educação Física a respeito da importância da criatividade em seu trabalho, de seu desejo de organizar aulas/atividades mais criativas e da forma como este objetivo poderia ser alcançado. A alternância das atividades realizadas, bem com a introdução de novos exercícios foi a forma como esses professores consideraram que poderiam promover a criatividade em suas atividades. Também Mariani e Alencar (2005) investigaram a percepção de 16 professores de História a respeito dos elementos do contexto do trabalho pedagógico favoráveis à expressão da criatividade em suas atividades docentes. Esses professores apontaram especialmente a necessidade de se ter liberdade para usar novas técnicas e abordagens do conteúdo que ministram, além da possibilidade para trabalhar com novos temas. Ressaltaram, ainda, a necessidade de recursos materiais e estrutura física adequada como elementos importantes para a expressão criativa do professor em seu trabalho docente.

Em outros estudos, com amostras de professores da educação superior, como os realizados por Oliveira e Alencar (2007) e Souza e Alencar (2006), foram também identificados procedimentos pedagógicos que, segundo os professores, eram utilizados por eles para promover o desenvolvimento da criatividade do aluno. No primeiro deles, 20 docentes do curso de Letras foram entrevistados, tendo sido constatado que as práticas pedagógicas que acreditavam desenvolver a criatividade não eram intencionalmente adotadas, mas usados de forma intuitiva e esporádica para estimular a atenção dos alunos e motivá-los à disciplina. Por outro lado, Souza e Alencar, em estudo com 25 professores do curso de Pedagogia, verificaram que, segundo esses docentes, os mesmos utilizavam distintas práticas para promover a criatividade em sala de aula. Entretanto para apenas um número limitado desses professores, o currículo teórico e prático, adotado nas instituições onde trabalhavam, contemplava o desenvolvimento do potencial criativo do aluno.
Considerando o reduzido número de estudos e o fato de que o levantamento das crenças dos professores sobre procedimentos úteis para desenvolver a criatividade possibilitaria não apenas identificar concepções errôneas sobre práticas pedagógicas que favorecem a criatividade a serem desfeitas, mas também identificar lacunas em seu conhecimento sobre práticas docentes facilitadoras do desenvolvimento e expressão do potencial criador, desenvolveu-se o presente estudo. Este teve como objetivo construir e validar uma escala de práticas pedagógicas para a criatividade no ensino fundamental.

\section{MÉTODO}

\section{Participantes}

Participaram do estudo 398 professores, sendo 18 (4,5\%) do gênero masculino e 378 (95,0\%) do gênero feminino (dois participantes deixaram de informar o gênero). Oitenta e nove desses professores lecionavam na $1^{\mathrm{a}}$ série, 73 na $2^{\mathrm{a}}$. série, 69 na $3^{\mathrm{a}}$. série e 58 na $4^{\mathrm{a}}$. série do ensino fundamental. Os demais informaram que lecionavam em mais de uma dessas séries ou ainda também na pré-escola ou em outras séries do ensino básico. Quanto à escolaridade, 61 (15,3\%) informaram ter o curso normal, 259 (65,1\%) o curso superior, $72(18,1 \%)$ especialização e $3(0,8 \%)$ o mestrado. Três participantes não indicaram a sua escolaridade. Entre os 334 que informaram ter cursado graduação e/ou pós-graduação, 308 indicaram o curso superior realizado. Entre estes, 222 (55,8\%) haviam cursado Pedagogia ou curso similar (como Escola Superior de Educação), 27 (6,8\%) Letras e 26 (6,5\%) Estudos Sociais. Os demais indicaram Educação Artística (7), Psicologia (6), Educação Física (5), Matemática (4), Biologia (2), Economia (1), Filosofia (1), Computação (1), ou dois ou mais cursos superiores (6).

Entre os 398 professores, 205 (51,5\%) lecionavam em escolas públicas e 190 (47,7\%) em escolas particulares. Três professores deixaram de informar o tipo de escola na qual trabalhavam. Cento e sessenta e quatro $(41,2 \%)$ desses professores lecionavam em escolas do Plano Piloto de Brasília, cuja população é predominantemente de status sócio-econômico médio e 176 (44,2\%) em escolas localizadas em outras regiões administrativas do Distrito Federal e 5 (1,3\%) em zona rural. Não foi possível identificar o local de trabalho nos questionários de 53 (13,3\%) professores.

A idade média dos participantes foi de 34,08 ( $\mathrm{DP}=8,39)$, variando de 18 a 64, com tempo médio de magistério de 11,36 anos (DP=6,59). 


\section{Etapas da Construção do Instrumento e Procedimentos de Coleta de Dados}

A escala, em sua versão inicial, incluiu 38 itens referentes a práticas docentes, a serem avaliadas pelo professor quanto à extensão em que considerava que tais práticas favoreciam o desenvolvimento da criatividade do aluno. A mesma foi construída com base em estudos teóricos e empíricos a respeito de atividades e procedimentos pedagógicos que promovem ou inibem o desenvolvimento e expressão da criatividade do aluno (Alencar, 1993, 1995, 1999a, 1999b, 2001; Alencar \& Fleith, 2004; Craft, 1998; Cropley, 1997; Fleith, 2000, 2001; Fryer \& Collings, 1991; Furman, 1998; Martinez, 2002; Morgan \& Foster, 1999; Soh, 2000; Tan, 2001; Torrance, 1970, 1992, 1995). Nas instruções, é solicitado ao professor para avaliar cada item em uma escala de quatro pontos. O número 4 corresponde a que a prática favorece muito este desenvolvimento; o número 3 que favorece moderadamente; o número 2 que pouco favorece e o número 1 que nada favorece.

A versão preliminar da escala passou pelo escrutínio de estudantes de graduação e pós-graduação que participavam de um grupo de pesquisa coordenado pelas autoras do presente estudo e por uma pesquisadora da área de criatividade no contexto educacional. A seguir, foi realizado um estudo piloto com o objetivo de avaliar semanticamente os itens da escala, buscando-se, desta forma, assegurar a sua compreensão, evitar ambigüidade e formulações pouco apropriadas. Participaram do estudo piloto 16 professores das quatro primeiras séries do ensino fundamental. Estes responderam o instrumento individualmente no sentido de facilitar a identificação dos itens a serem revistos. Procedeu-se, então, a reformulação daqueles que foram considerados pouco claros, ambíguos ou com conteúdo similar a algum outro item da escala.

Após esta etapa, o instrumento foi aplicado aos participantes do presente estudo. O mesmo foi respondido de forma individual ou coletiva (em reuniões de coordenação), sempre na presença do pesquisador (bolsistas de Iniciação Científica e outros estudantes que integravam o grupo de pesquisa no momento em que os dados foram coletados).

\section{Análise dos Dados}

Foi inicialmente estabelecida a validade de construto da escala, verificando-se a sua estrutura interna por meio de análise fatorial. Foi utilizado o pacote estatístico SPSS, realizando-se uma análise fatorial dos eixos principais, com rotação varimax. Antes de se proceder à análise fatorial, foi feita uma análise exploratória dos dados, com o objetivo de examinar os distintos pressupostos subjacentes à análise fatorial. Os pressupostos foram atendidos. O KMO foi de 0,82 e o teste de esfericidade de Bartlett foi significativo $(\mathrm{p}=0,0001)$. Não foram encontrados mais do que $4,27 \%$ de casos omissos por variável. Para verificar a consistência interna dos fatores gerados foi utilizado o coeficiente alfa.

\section{RESULTADOS}

Inicialmente, 10 fatores foram extraídos com base no critério de Kaiser (Gable \& Wolf, 1993), em que o eigenvalue do fator deve ser igual ou maior que 1. Entretanto, três fatores foram descartados. Um, por incluir quatro itens presentes também em outros fatores, e outros dois, cada um com três itens, por terem apresentado um coeficiente alfa de consistência interno baixo $(0,42$ e 0,36$)$. Ademais, integraram os fatores apenas os itens com carga fatorial igual ou maior que 0,30 .

Os seguintes itens foram descartados: item 1, ajudar os alunos a aprenderem com os seus erros; item 2, fazer perguntas que instiguem a curiosidade dos alunos; item 5, elogiar os alunos que apresentam uma idéia diferente da apresentada pelos colegas; item 10, utilizar exercícios que permitem aos alunos dar respostas originais; item 11, estimular a curiosidade dos alunos por meio das tarefas propostas em sala de aula; item 13, encorajar os alunos a defenderem suas idéias a respeito de questões que estejam sendo abordadas em aula; item 14, dar oportunidades aos alunos de escolherem a atividade a ser desenvolvida; item 15, estimular a imaginação dos alunos; item 20, desenvolver atividades artísticas em sala de aula; item 21, fazer conexões entre o que está sendo abordado em sala de aula com outros temas da atualidade. A solução de sete fatores explicou $29,7 \%$ da variância.

O fator 1, denominado Estímulo à Produção de Novas Idéias, inclui cinco itens relativos a estratégias utilizadas pelo professor para favorecer a produção de novas idéias pelos alunos. $\mathrm{O}$ fator 2 , denominado Interesse pela Aprendizagem do Aluno, inclui cinco itens, que dizem respeito ao interesse docente em assegurar a aprendizagem dos alunos (veja Tabelas 1 e 2). 
TABELA 1

Cargas Fatoriais, Comunalidades e Correlações Item-Total dos Itens que Integram o Fator 1 (Estímulo à Produção de Novas Idéias)

\begin{tabular}{|c|c|c|c|c|}
\hline Item & Conteúdo & Carga & $h^{2}$ & Correlação item-total \\
\hline 18 & Variar a forma de ministrar as aulas. & 0,74 & 0,76 & 0,55 \\
\hline 16 & Propor problemas que tenham mais de uma solução para os alunos. & 0,50 & 0,50 & 0,46 \\
\hline 17 & Fazer perguntas que levem os alunos a raciocinarem. & 0,49 & 0,36 & 0,38 \\
\hline 25 & Fazer uso de formas diversificadas de avaliação de aprendizagem. & 0,41 & 0,56 & 0,46 \\
\hline 22 & Dar oportunidade para os alunos discordarem do ponto de vista do(a) professor(a). & 0,34 & 0,36 & 0,44 \\
\hline
\end{tabular}

Nota. Variância explicada=5,50. Índice alfa=0,69.

TABELA 2

Cargas Fatoriais, Comunalidades e Correlações Item-Total dos Itens que Integram o Fator 2 (Interesse pela Aprendizagem do Aluno)

\begin{tabular}{llccc}
\hline Item & \multicolumn{1}{c}{ Conteúdo } & Carga & $\mathrm{h}^{2}$ & Correlação item-total \\
\hline 27 & Relacionar temas abordados em sala com outros já focalizados em aulas anteriores. & 0,52 & 0,38 & 0,45 \\
29 & Esclarecer as dúvidas dos alunos quando estas forem apresentadas. & 0,50 & 0,42 & 0,43 \\
28 & Utilizar exemplos para ilustrar o que está sendo abordado em classe. & 0,44 & 0,42 & 0,50 \\
23 & Encorajar os alunos a demonstrarem conhecimentos que já possuem a respeito de & 0,39 & 0,38 & 0,39 \\
& um novo conteúdo. & 0,30 & 0,37 & 0,36 \\
\hline
\end{tabular}

Nota. Variância explicada=5,34. Índice alfa=0,67.

O fator 3, denominado Participação do Aluno em Sala de Aula, inclui quatro itens relativos a práticas pedagógicas utilizadas pelo professor para facilitar a participação do aluno em classe. $\mathrm{O}$ fator 4 , denomina- do Incentivo à Autoconfiança do Aluno, inclui três itens referentes a condutas do professor para fazer com que o aluno tenha confiança em si mesmo (veja Tabelas 3 e 4).

TABELA 3

Cargas Fatoriais, Comunalidades e Correlações Item-Total dos Itens que Integram o Fator 3 (Participação do Aluno em Sala de Aula)

\begin{tabular}{llccc}
\hline Item & Conteúdo & Carga & h $^{2}$ & Correlação item-total \\
\hline 3 & Implementar atividades em sala de aula que requeiram ativa participação dos alunos. & 0,60 & 0,47 & 0,36 \\
4 & Levar em consideração interesses dos alunos. & 0,53 & 0,31 & 0,36 \\
12 & Fazer somente críticas construtivas a seus alunos. & 0,46 & 0,25 & 0,33 \\
7 & Ouvir as sugestões dos alunos, mesmo quando elas não sejam úteis. & 0,43 & 0,29 & 0,29 \\
\hline
\end{tabular}

Nota. Variância explicada=4,89. Índice alfa=0,51.

TABELA 4

Cargas Fatoriais, Comunalidades e Correlações Item-Total dos Itens que Integram o Fator 4 (Incentivo à Autoconfiança do Aluno)

\begin{tabular}{llccc}
\hline Item & Conteúdo & Carga & $h^{2}$ & Correlação item-total \\
\hline 31 & Encorajar os alunos a exporem suas idéias no decorrer das atividades em classe. & 0,74 & 0,69 & 0,53 \\
24 & Instigar no aluno confiança em sua competência/capacidade. & 0,47 & 0,46 & 0,52 \\
32 & Estimular a capacidade crítica do aluno. & 0,30 & 0,49 & 0,45 \\
\hline
\end{tabular}

Nota. Variância explicada=4,31. Índice alfa=0,68.

O fator 5, denominado Procedimentos Tradicionais de Ensino, inclui quatro itens referentes a práticas pedagógicas comuns no modelo tradicional de ensino. O fator 6, denominado Valorização das Idéias Dis- 
centes, inclui três itens relativos a práticas docentes voltadas para a valorização das idéias dos alunos. O fator 7, denominado Promoção da Auto-Avaliação
Discente, consta de dois itens referentes à avaliação pelo aluno de seu desempenho (veja Tabelas de 5 a 7 ).

TABELA 5

Cargas Fatoriais, Comunalidades e Correlações Item-Total dos Itens que Integram o Fator 5 (Procedimentos Tradicionais de Ensino)

\begin{tabular}{llccc}
\hline Item & Conteúdo & Carga & $\mathrm{h}^{2}$ & Correlação item-total \\
\hline 6 & Verificar se os alunos responderam corretamente os exercícios referentes a cada & 0,59 & 0,41 & 0,44 \\
& unidade do programa. & & & \\
9 & Ministrar aulas expositivas a respeito dos tópicos do programa. & 0,54 & 0,32 & 0,38 \\
19 & Repreender os alunos que não obedecem as ordens do(a) professor(a). & 0,47 & 0,29 & 0,38 \\
8 & Repreender os alunos que fazem muitas perguntas. & 0,46 & 0,33 & 0,28 \\
\hline
\end{tabular}

Nota. Variância explicada=3,86. Índice alfa=0,58.

TABELA 6

Cargas Fatoriais, Comunalidades e Correlações Item-Total dos Itens que Integram o Fator 6 (Valorização das Idéias Discentes)

\begin{tabular}{llccc}
\hline Item & Conteúdo & Carga & $h^{2}$ & Correlação item-total \\
\hline 35 & Aproveitar as idéias dos alunos sempre que possível. & 0,62 & 0,41 & 0,43 \\
34 & Estimular os alunos a expressarem suas próprias idéias. & 0,53 & 0,41 & 0,34 \\
36 & Desenvolver atividades fora da sala de aula em diversos ambientes. & 0,33 & 0,33 & 0,33 \\
\hline
\end{tabular}

Nota. Variância explicada=3,19. Índice alfa $=0,60$.

TABELA 7

Cargas Fatoriais, Comunalidades, Correlações Item-Total dos Itens que Integram o Fator 7 (Promoção da Auto-Avaliação Discente)

\begin{tabular}{llccc}
\hline Item & Conteúdo & Carga & $\mathrm{h}^{2}$ & Correlação item-total \\
\hline 30 & Encorajar os alunos a avaliarem seu próprio trabalho. & 0,42 & 0,45 & 0,50 \\
33 & Envolver os alunos no processo de avaliação de seu desempenho. & 0,38 & 0,45 & 0,44 \\
\hline
\end{tabular}

Nota. Variância explicada=2,58. Índice alfa=0,60

Utilizou-se o coeficiente alfa para avaliar a consistência interna de cada fator. Foram obtidos os seguintes coeficientes alfa: 0,69 para o fator 1, 0,67 para o fator 2, 0,51 para o fator 3, 0,68 para o fator 4, 0,58, para o fator 5 e 0,60 para os fatores 6 e 7 . A correlação item-total variou de 0,28 a 0,55 . Em sua versão final, a escala incluiu 26 itens distribuídos em sete fatores.

\section{DISCUSSÃO}

Entre os fatores que compõem a escala descrita no presente estudo, especialmente três deles - Estímulo à Produção de Novas Idéias, Incentivo à Autoconfiança do Aluno e Valorização das Idéias Discente - incluem itens que a literatura de criatividade no contexto educacional (Alencar, 1999b, 2001, 2002, 2004; Alencar \& Fleith, 2003; Cropley, 1997, 2005; Cropley \& Urban, 2000; Fleith, 2001; Martinez, 2002; Nickerson, 1999; Tan, 2001; Torrance, 1970, 1995; Wechsler,
2001) têm indicado como práticas docentes favorecedoras do desenvolvimento e expressão da criatividade do aluno. Exemplos desses itens são: "Propor problemas que tenham mais de uma solução para os alunos”, "Instigar no aluno confiança em sua competência/capacidade" e "Estimular os alunos a expressarem suas próprias idéias”.

Dois fatores - Interesse pela Aprendizagem do Aluno e Participação do Aluno em Sala de Aula estão relacionados prioritariamente a procedimentos docentes que facilitam a aprendizagem de conteúdos mais do que a promoção da criatividade. Alguns exemplos de itens destes fatores são: "Encorajar os alunos a demonstrarem conhecimentos que já possuem a respeito de um novo conteúdo", "Relacionar temas abordados em sala com outros já focalizados em aulas anteriores", "Esclarecer as dúvidas dos alunos quando estas forem apresentadas” e "Levar em consideração interesses dos alunos”. 
A escala incluiu também um fator com itens relativos à auto-avaliação discente, como, por exemplo, "Encorajar os alunos a avaliarem seu próprio trabalho" e outro fator - Procedimentos Tradicionais de Ensino - com práticas pedagógicas mais freqüentemente observadas no modelo tradicional de ensino.

Os fatores gerados neste estudo de validação assemelham-se aos avaliados pelo Inventário de Práticas Docentes que Favorecem a Criatividade no Ensino Superior (Alencar \& Fleith, 2004) e pela Escala sobre o Clima para Criatividade em Sala de Aula (Fleith \& Alencar, 2005), esta última direcionada a alunos de $3^{\mathrm{a}}$. e $4^{\mathrm{a}}$ séries do eEnsino fundamental, especialmente àqueles que dizem respeito ao interesse pela aprendizagem do aluno, incentivo a novas idéias e clima acolhedor à expressão de idéias dos alunos. Isto nos leva a levantar a hipótese de que existem práticas educacionais favoráveis à criatividade que devem ser implementadas pelos professores independentes do nível de ensino em que atuam. Estes resultados estão em consonância com a literatura da área que não sugere práticas pedagógicas específicas para um nível de ensino (Amabile, 1989; Cropley, 1997, 2005; Starko, 1995; Virgolim, 2007).

É relevante destacar que o estudo de validação da escala indicou que o índice (alfa) de consistência interna dos distintos fatores esteve aquém do recomendado. Segundo Gable e Wolf (1993), um dos critérios de retenção de fator é terem os seus itens carga fatorial igual ou maior do que 0,30, critério este que foi atendido. Um segundo critério, é apresentar o coeficiente alfa com valor igual ou maior do que 0,70 , o que não foi encontrado. Dada esta limitação, considera-se que a presente escala seja revisada e novos itens sejam incluídos, sendo, a seguir, novamente utilizada em amostras de professores do ensino fundamental, com vistas a aumentar o índice de consistência interna dos fatores. Ademais, seria recomendável ampliar o tamanho da amostra, com vistas a assegurar uma maior representatividade.

Ressalta-se que uma das vantagens de se ter disponível para uso uma escala, como a proposta no presente estudo, é por esta permitir a identificação das práticas pedagógicas consideradas pelo professor como mais relevantes para se favorecer a capacidade de criar de seus alunos. Isto poderia contribuir para a identificação de possíveis idéias errôneas do professor a respeito de como promover a criatividade em sala de aula. Uma vez identificadas essas idéias, poder-se-iam propor intervenções, por meio de cursos ou oficinas, que orientem o docente no sentido de uma atuação em sala de aula promotora da expressão criativa do aluno. Como apontam distintos autores (Alencar \& Fleith, 2003; Cropley, 1997, 2005; Cropley \& Urban, 2000; Martinez, 2002; Tan, 2001), preparar o aluno para ser um pensador criativo e independente é algo necessário neste atual momento da História. Este se caracteriza por extrema complexidade, incerteza, instabilidade e imprevisibilidade, exigindo do profissional, independentemente de sua área de atuação, alta capacidade de inovação e adaptação à mudança. Ademais, a expressão criativa contribui positivamente para a qualidade de vida e bem-estar emocional do indivíduo, que é algo que a escola deve promover.

\section{REFERÊNCIAS}

Alencar, E. M. L. S. (1993). Thinking in the future: The need to promote creativity in the educational context. Gifted Education International, 9, 93-96.

Alencar, E. M. L. S. (1995). Criatividade. Brasília: Editora da UnB.

Alencar, E. M. L. S. (1999a, agosto). Mastering creativity for education in the 21 st century. Palestra proferida no $13^{\text {th }}$ Biennial Conference, World Council for Gifted and Talented Children, Istambul, Turquia.

Alencar, E. M. L. S. (1999b). Educación para la creatividad. Educación, 10, 102-109.

Alencar, E. M. L. S. (2001). Criatividade e a educação do superdotado. Petrópolis: Vozes.

Alencar, E. M. L. S. (2002). O estímulo à criatividade em programas de pós-graduação segundo seus estudantes. Psicologia: Reflexão e Crítica, 15, 63-69.

Alencar, E. M. L. S. (2004). Como desenvolver o potencial criador (10 ed.). Petrópolis: Vozes.

Alencar, E. M. L. S., \& Fleith, D. S. (2003). Criatividade: Múltiplas perspectivas. Brasília: Editora da UnB.

Alencar, E. M. L. S., \& Fleith, D. S. (2004). Inventário de práticas docentes que favorecem a criatividade no ensino superior. Psicologia: Reflexão e Crítica, 17, 105-110.

Amabile, T. M. (1983). The social psychology of creativity. New York: Springer.

Amabile, T. M. (1989). Growing up creative. Buffalo, NY: Creative Education Foundation.

Amabile, T. M. (1990). Within you, without you: Towards a social psychology of creativity and beyond. Em M. A. Runco \& R. S. Albert (Orgs.), Theories of creativity (pp. 61-91). Newbury Park, CA: Sage.

Amabile, T. M. (1996). Creativity in context. Boulder, CO: Westview Press.

Amabile, T. M. (2001). Beyond talent: John Irving and the passionate craft of creativity. American Psychologist, 56, 333-336. 
Craft, A. (1998). Educator perspectives on creativity: An English study. The Journal of Creative Behavior, 32, 244-257.

Craft, A. (2005). Creativity in schools: Tensions and dilemmas. London: Routledge.

Cropley, A. J. (1997). Fostering creativity in the classroom: General principles. Em M. A. Runco (Org.), The creativity research handbook (pp. 83-114). Creskill, NJ: Hampton Press.

Cropley, A. J. (2005). Creativity in education \& learning. London: RoutledgeFalmer.

Cropley, A. J., \& Urban, K. K. (2000). Programs and strategies for nurturing creativity. Em K. A. Heller, F. J. Monks, R. J. Sternberg \& R. F. Subotnik (Orgs.), International handbook of giftedness and talent ( $2^{\mathrm{a}}$ ed., pp. 485-498). Oxford: Elsevier Science.

Csikszentmihalyi, M. (1988). Society, culture, and person: A systems view of creativity. Em R. J. Sternberg (Org.), The nature of creativity (pp. 313-339). New York: Cambridge University Press.

Csikszentmihalyi, M. (1994). The domain of creativity. Em D. H. Feldman, M. Csikszentmihalyi \& H. Gardner (Orgs.), Changing the world: A framework for the study of creativity (pp. 135158). Westport, CT: Praeger.

Csikszentmihalyi, M. (1995). Creativity. New York: Harper Collins.

Csikszentmihalyi, M. (1999). Implications of a systems perspective for the study of creativity. Em R. J. Sternberg (Org.), Handbook of creativity (pp. 313-335). New York: Cambridge University Press.

Fleith, D. S. (2000). Teacher and student perceptions of creativity in the classroom environment. Roeper Review, 22, 148-153.

Fleith, D. S. (2001). Criatividade: Novos conceitos e idéias Aplicabilidade à educação. Cadernos de Educação Especial, 17, 55-61.

Fleith, D. S., \& Alencar, E. M. L. S. (2005). Escala sobre o clima para criatividade em sala de aula. Psicologia: Teoria e Pesquisa, 21, 85-91.

Fryer, M., \& Collings, J. A. (1991). British views of creativity. The Journal of Creative Behavior, 25, 75-81.

Furman, A. (1998). Teacher and pupil characteristics in the perception of the creativity of classroom climate. The Journal of Creative Behavior, 32, 258-275.

Gable, R. K., \& Wolf, M. B. (1993). Instrument development in the affective domain ( $2^{\mathrm{a}}$ ed.). Norwell, MA: Kluwer Academic.

Guilford, J. P. (1950). Creativity. American Psychologist, 5, 444454.

Isaksen, S. G. (1987). Introduction - An orientation to the frontiers of creativity research. Em S. G. Isaksen (Org.), Frontiers of creativity research (pp. 1-26). Buffalo, NY: Bearly.

Hill, K. G., \& Amabile, T. M. (1993). A social psychological perspective on creativity: Intrinsic motivation and creativity in the classroom and workplace. Em S. G. Isaksen, M. G. Murdock, R. L. Firestein \& D. Treffinger (Orgs.), Understanding and recognizing creativity: The emergence of a discipline (pp. 400-432). Norwood, NJ: Ablex.
Mariani, M. F. M., \& Alencar, E. M. L. S. (2005). Criatividade e trabalho pedagógico segundo professores de História: Limites e possibilidades. Psicologia Escolar e Educacional, 9, 27-36.

Martinez, A. M. (2002). A criatividade na escola: Três direções de trabalho. Linhas Críticas, 8, 189-206.

Melo, A. C. R. (2001). Educação física adaptada e criatividade: Uma investigação sobre a opinião dos professores. Dissertação de mestrado não-publicada, Universidade Católica de Brasília.

Morgan, S., \& Foster, J. (1999). Creativity in the classroom. Gifted Education International, 14, 29-43.

Nickerson, R. S. (1999). Enhancing creativity. Em R. J. Sternberg (Org.), Handbook of creativity (pp. 392-430). Cambridge: Cambridge University Press.

Oliveira, Z. M. F., \& Alencar, E. M. L. S. (2007). Criatividade na formação e atuação do professor do curso de Letras. Manuscrito submetido para publicação.

Runco, M. A. (2004). Creativity. Annual Review of Psychology, $55,657-687$.

Soh, K. C. (2000). Indexing creativity fostering teacher behavior: A preliminary validation study. The Journal of Creative Behavior, 34, 118-134.

Souza, M. E. M. G., \& Alencar, E. M. L. S. (2006). O curso de Pedagogia e condições para o desenvolvimento da criatividade. Psicologia Escolar e Educacional, 10, 21-30.

Starko, A. J. (1995). Creativity in the classroom. White Plains, NY: Longman.

Sternberg, R. J. (1988). A three-facet model of creativity. Em R. J. Sternberg (Org.), The nature of creativity: Contemporary psychological approaches (pp. 125-147). Cambridge: Cambridge University Press.

Sternberg, R. J. (1991, agosto). A theory of creativity. Trabalho apresentado no XIV School Psychology Association, Colloquium. Braga, Portugal.

Sternberg, R. J., \& Lubart, T. I. (1991). An investment theory of creativity and its development. Human Development, 34, 1-31.

Sternberg, R. J., \& Lubart, T. I. (1993). Creative giftedness: A multivariate investment approach. Gifted Child Quarterly, 37(3), 7-15.

Sternberg, R. J., \& Lubart, T. I. (1995). Defying the crowd: Cultivating creativity in a culture of conformity. New York: The Free Press.

Sternberg, R. J., \& Lubart, T. I. (1996). Investing in creativity. American Psychologist, 51, 677-688.

Tan, A. G. (2001). Singaporean teachers' perception of activities useful for fostering creativity. The Journal of Creative Behavior, 35, 131-148.

Torrance, E. P. (1970). Encouraging creativity in the classroom. Dubuque, IA: C. Brown.

Torrance, E. P. (1992). A national climate for creativity and invention. Gifted Child Today, 15, 10-14.

Torrance, E. P. (1993). Experiences in developing technology for creative education. Em S. G. Isaksen, M. C. Murdock, R. L. Firestien \& D. J. Treffinger (Orgs.), Understanding and recog- 
nizing creativity: The emergence of a discipline (pp. 158-201). Norwood, NJ: Ablex.

Torrance, E. P. (1995). Why fly? A philosophy of creativity. Norwood, NJ: Ablex.

Urban, K. K. (1990). Recent trends in creativity research and theory in western Europe. European Journal for High Ability, 1, 99-113.

Virgolim, A. M. R. (Org.). (2007). Talento criativo: Expressão em múltiplos contextos. Brasília: Editora da UnB.
Wechsler, S. M. (2001). A educação criativa: Possibilidades para descoberta. Em S. Castanho \& M. E. Castanho (Orgs.), Temas e textos em metodologia do ensino superior (pp. 165-170). Campinas: Papirus.

Nota:

${ }^{1}$ Agradecemos o apoio recebido do CNPq para desenvolvimento do estudo.

\section{Sobre as autoras:}

Eunice Maria Lima Soriano de Alencar: Professora do Programa de Mestrado em Educação da Universidade de Brasília. Bolsista do CNPq.

Denise Souza Fleith: Professora do Programa de Pós-graduação em Processos de Desenvolvimento Humano e Saúde do Instituto de Psicologia da Universidade de Brasília. Pesquisadora do CNPq.

Endereço para correspondência: Eunice Maria Lima Soriano de Alencar - Programa de Mestrado em Educação da Universidade Católica de Brasília. Endereço eletrônico: ealencar@pos.ucb.br. 